\title{
Tuning the Size and Shape of NanoMOFs via Templated Electrodeposition and Subsequent Electrochemical Oxidation
}

Francesco Caddeo, ${ }^{\dagger}$ Rebekka Vogt, ${ }^{\ddagger}$, Dominik Weil $, ~^{\ddagger}, \S$ Wilfried Sigle, ${ }^{\|}$M. Eugenia Toimil-Molares, ${ }^{*}$, and A. Wouter Maijenburg*,,$++(10$

†ZIK SiLi-nano, Martin-Luther-University Halle-Wittenberg, Karl-Freiherr-von-Fritsch-Straße 3, 06120 Halle (Saale), Germany
${ }^{\ddagger}$ Materials Research Department, GSI Helmholtz Centre for Heavy Ion Research, Planckstraße 1, 64291 Darmstadt, Germany
${ }^{\S}$ Material-und Geowissenschaften, Technische Universität Darmstadt, Alarich-Weiss-Straße 2, 64287 Darmstadt, Germany
${ }^{\|}$Stuttgart Center for Electron Microscopy (StEM), MPI for Solid State Research, Heisenbergstraße 1, 70569 Stuttgart, Germany

Supporting Information

ABSTRACT: The control over the size and shape of nanoMOFs is essential for their exploitation in integrated devices such as sensors, membranes for gas separation, photoelectrodes, etc. Here, we demonstrate the synthesis of nanowires and three-dimensionally interconnected nanowire networks of $\mathrm{Cu}$-based metal-organic frameworks (MOFs) by a combination of ion-track technology and electrochemical methods. In particular, $\mathrm{Cu}$ nanowires and nanowire networks were electrodeposited inside polymeric etched ion-track membranes and subsequently converted by electrochemical oxidation into different $\mathrm{Cu}$-based MOFs such as the wellknown $\mathrm{Cu}_{3}(\mathrm{BTC})_{2}$ (also known as HKUST-1) and the lesser-

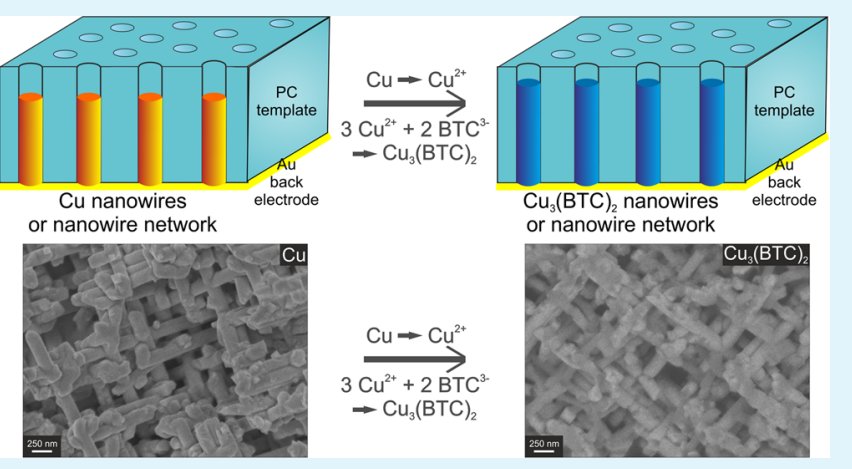
known MOF $\mathrm{Cu}(\mathrm{INA})_{2}$. The MOFs are formed inside the template, therefore adopting the shape of the host nanochannels. The synthesized MOF nanowires exhibit tunable diameters between 80 and $260 \mathrm{~nm}$. Characterization by X-ray diffraction, thermogravimetric analysis/differential scanning calorimetry, scanning electron microscopy, and transmission electron microscopy indicates that the employed electrochemical conversion includes the formation of $\mathrm{Cu}_{2} \mathrm{O}$ as an intermediate, as well as the initial formation of an amorphous MOF phase, which crystallizes upon longer reaction times.

KEYWORDS: nanoMOFs, MOF nanowires, nanowire networks, anodic oxidation, HKUST-1

\section{INTRODUCTION}

Metal-organic frameworks (MOFs) are a class of crystalline materials that enjoyed a tremendous development mainly due to their unique properties such as extremely high internal surface area, permanent open porosity, high crystallinity, and easy chemical functionalization. ${ }^{1-3}$ Due to their versatility, MOFs are highly promising for a wide range of technologically important applications, such as gas storage, ${ }^{4}$ gas separation, ${ }^{5}$ sensing, ${ }^{6}$ biomedical applications, ${ }^{7}$ thermoelectrics, ${ }^{8}$ and heterogeneous (photo) catalysis. $^{9-13}$

Recently, increasing efforts were devoted toward the development of synthetic routes that enable downsizing MOF crystals at the nanoscale regime. ${ }^{14}$ This is due to the need to exploit the full potential of MOFs for specific applications, in particular in heterogeneous (photo)catalysis, since the activity of these microporous materials might be limited by the slow diffusion of chemical species toward the center of the MOF crystals. These so-called "nanoMOFs" are synthesized using synthetic strategies such as microwave synthesis, ${ }^{15}$ sonochemical synthesis, ${ }^{16}$ solvothermal synthesis, ${ }^{17}$ microemulsions, ${ }^{18}$ and droplet-based microfluid syn- thesis. ${ }^{19}$ Recently, an exhaustive review was published on this topic by Farha et al. ${ }^{20}$ However, these methods rely on the control over the nucleation and growth processes of MOF crystals through variations of synthetic parameters such as the concentration of modulating agents, temperature, reaction volume, time, etc. Even though an extensive control over the size of nanoMOFs has been achieved in some cases, ${ }^{15,21}$ the control of the shape of MOF nanocrystals and their assembly into more complex hierarchical structures are still challenging. In the case of HKUST-1, a two-step approach involving the formation of $\mathrm{Cu}(\mathrm{OH})_{2}$ nanotubes was developed to obtain HKUST-1 nanoparticle coatings on copper metal plates and three-dimensional architectures. $^{22}$

MOFs have also been synthesized by employing electrochemical methods. ${ }^{23,24}$ In particular, the anodic dissolution of a metallic substrate in an electrolyte containing the appropriate organic linker is an established technique for the preparation of

Received: March 12, 2019

Accepted: June 21, 2019

Published: June 21, 2019 

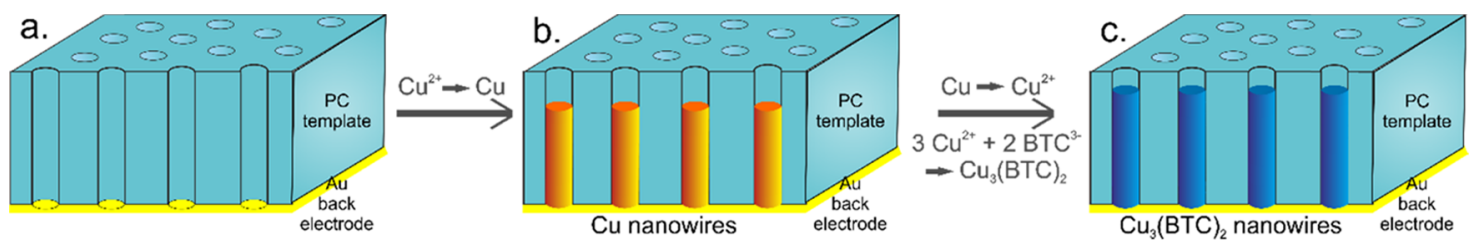

Figure 1. Schematic representation of the two-step synthesis process used for the formation of $\mathrm{Cu}_{3}(\mathrm{BTC})_{2}$ MOF nanowires. (a) Polycarbonate template with a conductive $\mathrm{Au}$ layer, (b) $\mathrm{Cu}$ nanowire growth via cathodic electrodeposition, and (c) anodic conversion of Cu nanowires to $\mathrm{Cu}_{3}(\mathrm{BTC})_{2}$ nanowires.

MOFs such as HKUST- $1,{ }^{25,26}$ MOF- $5,{ }^{27}$ MIL- $100,{ }^{28}$ ZIF- $8,{ }^{29}$ $\mathrm{Zr}$-based $\mathrm{UiO}-66,{ }^{30}$ etc. This method is mainly used for the preparation of MOF thin films on conductive substrates ${ }^{31}$ and has the advantage to produce highly crystalline MOFs using mild synthetic conditions (low temperatures and ambient pressures), nontoxic reaction media, and shorter reaction times. MOFs have also been deposited under cathodic bias ${ }^{32}$ or via patterned metallization and galvanic displacement on nonconductive substrates. ${ }^{33}$

On the other hand, ion-track technology allows the fabrication of porous polymer membranes. By swift heavy ion irradiation, and subsequent chemical etching of the generated ion tracks, membranes with tunable pore diameter $\left(\sim 20 \mathrm{~nm}\right.$ to several micrometers) and pore density $\left(1-10^{10}\right.$ pores $/ \mathrm{cm}^{2}$ ) are produced, exhibiting either parallel arrays of pores or highly interconnected pore networks. ${ }^{34}$ Electrodeposition inside these templates has been successfully used for the synthesis of metal or metal oxide nanowires, nanowire networks, and nanocones, ${ }^{35-38}$ whereby the nanowire length ( $100 \mathrm{~nm}$ to $100 \mu \mathrm{m}$ ) can be adjusted by the electrodeposition time. Regarding MOFs, the synthesis of one-dimensional zeolitic imidazole framework (ZIF-8) nanorods, nanotubes, and nanowires via interfacial synthesis using etched ion-track membranes has been recently reported. ${ }^{39}$

In this study, we combine for the first time two of the aforementioned techniques in a two-step synthetic approach where $\mathrm{Cu}$ nanowires are first electrodeposited inside the pores of etched ion-track membranes and subsequently electrochemically oxidized inside the same membrane in a solution of the appropriate organic linker, leading to the synthesis of nanowires and nanowire networks of the desired MOF. We first focus on the synthesis and characterization of nanowires of the well-known MOF $\mathrm{Cu}_{3}$ (BTC) $)_{2}$, also known as HKUST-1, which consists of $\mathrm{Cu}^{2+}$ ions organized in a paddle-wheel secondary building unit linked by 1,3,5-benzenetricarboxylate (BTC) molecules. ${ }^{40}$ In addition, we illustrate the versatility of this process by synthesizing $\mathrm{Cu}_{3}(\mathrm{BTC})_{2}$ nanowire networks in more complex nanochannel templates and $\mathrm{Cu}(\mathrm{INA})_{2}$ nanowires using isonicotinic acid (INA) as the organic linker. ${ }^{41}$ This procedure provides the unique opportunity to independently tune the shape, size and geometrical arrangement of onedimensional MOF nanostructures.

\section{RESULTS AND DISCUSSION}

Two-Step Electrochemical Synthesis of HKUST-1 Nanowires. Figure 1 shows a schematic representation of the two-step synthetic procedure used for the synthesis of $\mathrm{Cu}$ based MOF nanowires. Arrays of $\mathrm{Cu}$ nanowires were potentiostatically deposited within etched ion-track membranes with several different nanochannel diameters (Figure 1b). Subsequently, the $\mathrm{Cu}$ nanowire arrays embedded in the polymer template were employed as anodes for the formation of $\mathrm{Cu}_{3}(\mathrm{BTC})_{2}$ nanowires by oxidation of $\mathrm{Cu}$ to $\mathrm{Cu}^{2+}$ and the subsequent reaction of $\mathrm{Cu}^{2+}$ with $\mathrm{BTC}^{3-}$ (Figure 1c).

Figure 2 shows the oxidation currents recorded during the conversion of these $\mathrm{Cu}$ nanowires to $\mathrm{Cu}_{3}(\mathrm{BTC})_{2}$. For all

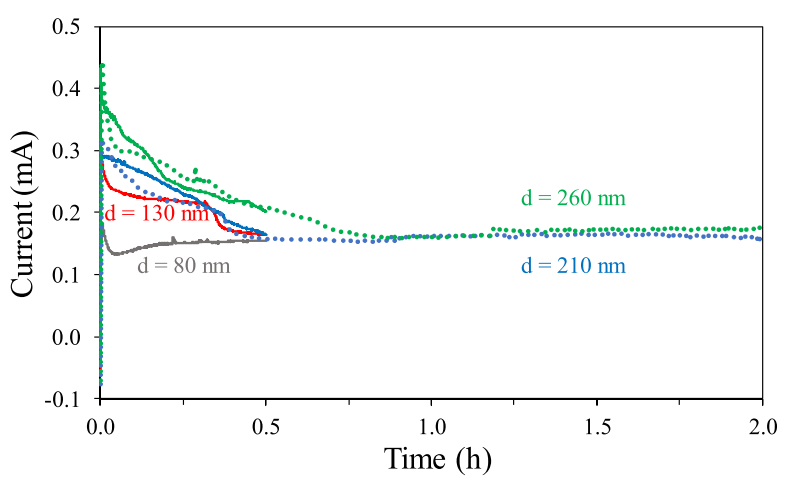

Figure 2. Chronoamperograms of the conversion of embedded arrays of $\mathrm{Cu}$ nanowires to $\mathrm{Cu}_{3}(\mathrm{BTC})_{2}$. The arrays exhibit different average nanowire diameters, namely, $80 \mathrm{~nm}$ (gray curve), $130 \mathrm{~nm}$ (red curve), $210 \mathrm{~nm}$ (blue curves), and $260 \mathrm{~nm}$ (green curves). The applied potential was $2.5 \mathrm{~V}$ vs $\mathrm{Cu}$, the temperature was $55{ }^{\circ} \mathrm{C}$, and the oxidation times were $30 \mathrm{~min}$ (solid curves) or $2 \mathrm{~h}$ (dashed curves).

curves, we observe an initial current of $0.2-0.4 \mathrm{~mA}$. As expected, the larger the nanochannel diameter, the larger the initial current value for the same potentiostatic oxidation conditions, indicating that the $\mathrm{Cu}$ wires were oxidized at similar rates. Furthermore, we observe that for all samples, the current stabilizes at a value of $\sim 150 \mu \mathrm{A}$. At this stage, we expect that the $\mathrm{Cu}$ nanowires have been completely oxidized and this steady-state current originates most likely from the splitting of the water used as the solvent. As shown in Figure S1, Supporting Information, similar steady-state currents were also observed in control experiments using empty templates in the same electrolyte. The curves in Figure 2 indicate that the thicker the nanowire, the longer the time needed to reach this steady-state current, i.e., to finish the conversion reaction. Thus, the steady-state current had not been reached after 30 min for the nanowires with diameters of 210 and $260 \mathrm{~nm}$ (solid green and blue lines in Figure 2). Therefore, arrays of $\mathrm{Cu}$ nanowires with a diameter larger than $200 \mathrm{~nm}$ were also oxidized for $2 \mathrm{~h}$ (dotted green and blue lines in Figure 2) to guarantee their complete conversion. These results indicate that the electrochemical conversion of $\mathrm{Cu}$ to $\mathrm{MOF}$ can be monitored in real time by the chronoamperometric curves.

Figure $3 \mathrm{a}$ shows the X-ray diffraction (XRD) patterns of $\mathrm{Cu}_{3}(\mathrm{BTC})_{2}$ nanowire arrays with diameters of 260 and $210 \mathrm{~nm}$ after $2 \mathrm{~h}$ of electrochemical conversion, still embedded in the polycarbonate template, together with a reference XRD pattern calculated from single-crystal XRD data published elsewhere. ${ }^{42}$ For clarity, the XRD patterns are shown in the $2 \theta$ range of 

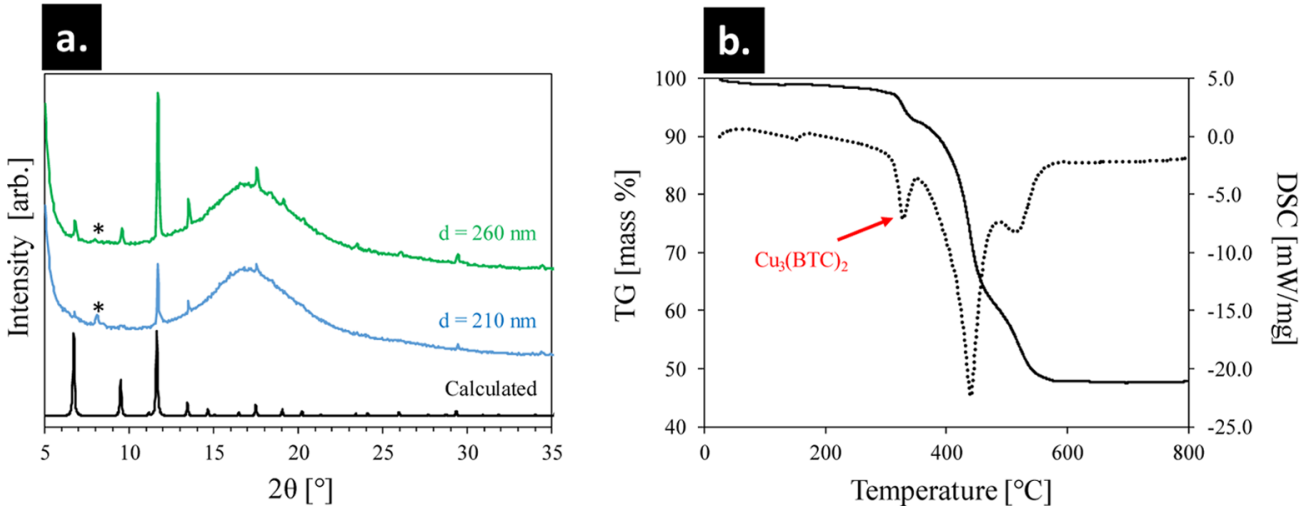

Figure 3. (a) XRD patterns of $\mathrm{Cu}_{3}(\mathrm{BTC})_{2}$ nanowires with diameters of $260 \mathrm{~nm}$ (green curve) and $210 \mathrm{~nm}$ (blue curve) after $2 \mathrm{~h}$ of electrochemical conversion and still embedded inside the polycarbonate template, and the calculated XRD pattern of $\mathrm{Cu}_{3}(\mathrm{BTC})_{2}$ (black line). ${ }^{42} *$ indicates a reflection identified as an amorphous phase of $\mathrm{Cu}_{3}(\mathrm{BTC})_{2}{ }^{43}$ (b) Thermogravimetric analysis/differential scanning calorimetry (TGA/DSC) curves of $\mathrm{Cu}_{3}(\mathrm{BTC})_{2}$ nanowires with a diameter of $210 \mathrm{~nm}$ still embedded within the pores of the polycarbonate membrane; solid line: TG; dashed line: DSC.
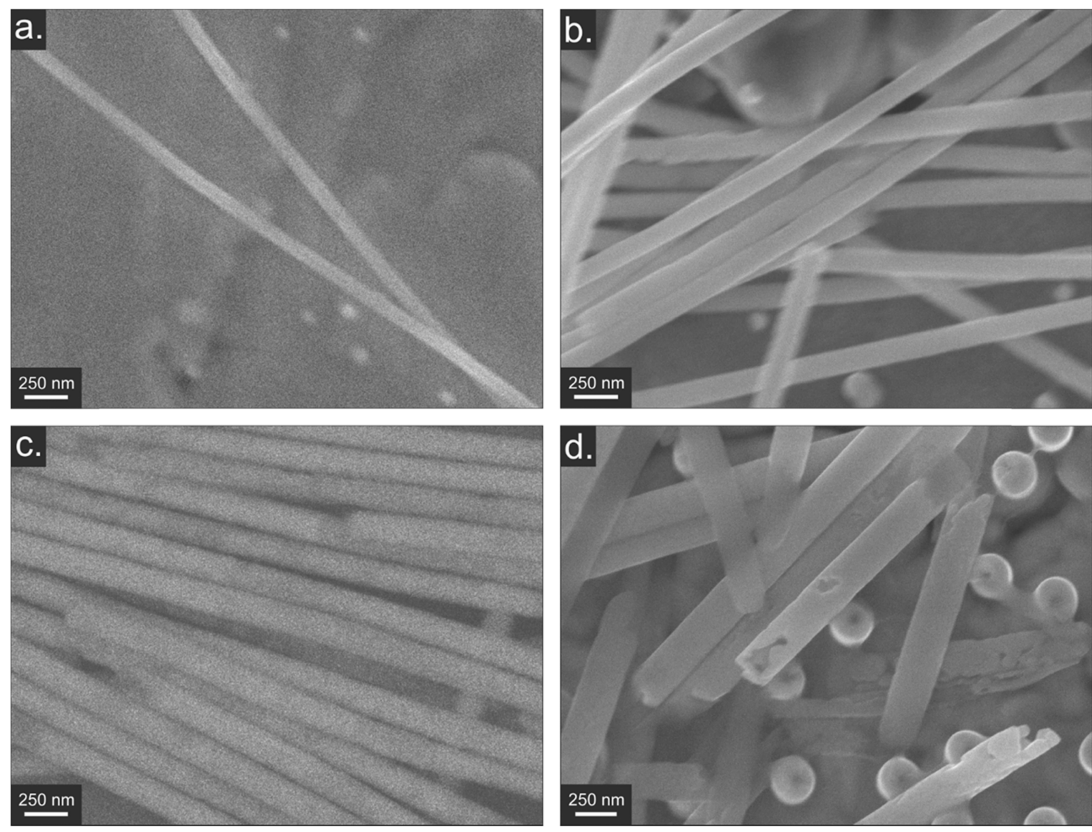

Figure 4. SEM images of $\mathrm{Cu}_{3}(\mathrm{BTC})_{2}$ MOF nanowires with diameters of (a) $80 \mathrm{~nm},(\mathrm{~b}) 130 \mathrm{~nm},(\mathrm{c}) 210 \mathrm{~nm}$, and (d) $260 \mathrm{~nm}$.

$5-35^{\circ}$, as the main reflections corresponding to the $\mathrm{Cu}_{3}(\mathrm{BTC})_{2}$ phase are present in this region. Since the MOF nanowires were still embedded within the template, all XRD patterns show the reflections corresponding to the $\mathrm{Cu}_{3}(\mathrm{BTC})_{2}$ phase superimposed to a broad halo due to the amorphous polycarbonate template (Figure S2). In both diffraction patterns, we were able to unambiguously determine the presence of the $\mathrm{Cu}_{3}(\mathrm{BTC})_{2}$ phase. The origin of the additional reflection found at $2 \theta \sim 8^{\circ}$ (marked by an asterisk) is still unknown. However, such a reflection had been previously reported by Liu et al. upon applying a dielectric-barrier discharge plasma treatment on $\mathrm{Cu}_{3}(\mathrm{BTC})_{2}{ }^{43}$

The complete XRD characterization of the $\mathrm{Cu}_{3}(\mathrm{BTC})_{2}$ nanowires is reported in Figures S3-S5 (Supporting Information). In the case of the nanowires synthesized by electrochemical oxidation for $30 \mathrm{~min}$ (Figure S3), the reflections corresponding to the $\mathrm{Cu}_{3}(\mathrm{BTC})_{2}$ crystalline phase appear only in the case of the nanowires with diameters of 210 and $260 \mathrm{~nm}$, whereas due to the limited amount of material for the nanowires with a smaller diameter, these reflections are hidden by the contribution of the polycarbonate membrane. In Figure S4, a comparison of the XRD patterns of the nanowires with a diameter of $260 \mathrm{~nm}$ after electrochemical oxidation for $30 \mathrm{~min}$ and $2 \mathrm{~h}$ is presented. The XRD pattern of the nanowires after $2 \mathrm{~h}$ of electrochemical oxidation shows that the reflection at $2 \theta \sim 8^{\circ}$, which is assigned to an unknown phase of $\mathrm{Cu}_{3}(\mathrm{BTC})_{2}$ in agreement with Liu et al., ${ }^{43}$ decreases substantially in intensity, whereas all of the reflections of crystalline $\mathrm{Cu}_{3}(\mathrm{BTC})_{2}$ are more intense and sharper. This suggests that $\mathrm{Cu}_{3}(\mathrm{BTC})_{2}$ nanocrystals grow at the expense of the unknown phase upon longer reaction times. Moreover, the XRD patterns in Figure $\mathrm{S} 3$ show the presence of $\mathrm{Cu}_{2} \mathrm{O}$ together with unconverted $\mathrm{Cu}$. As expected, the intensity of these reflections significantly decreased after $2 \mathrm{~h}$ of electrochemical oxidation (Figure S5), suggesting the full conversion of the $\mathrm{Cu}$ nanowires, which is in agreement with the chronoamperograms in Figure 2. It is also worth mentioning that the presence of $\mathrm{Cu}_{2} \mathrm{O}$ during the electrochemical 

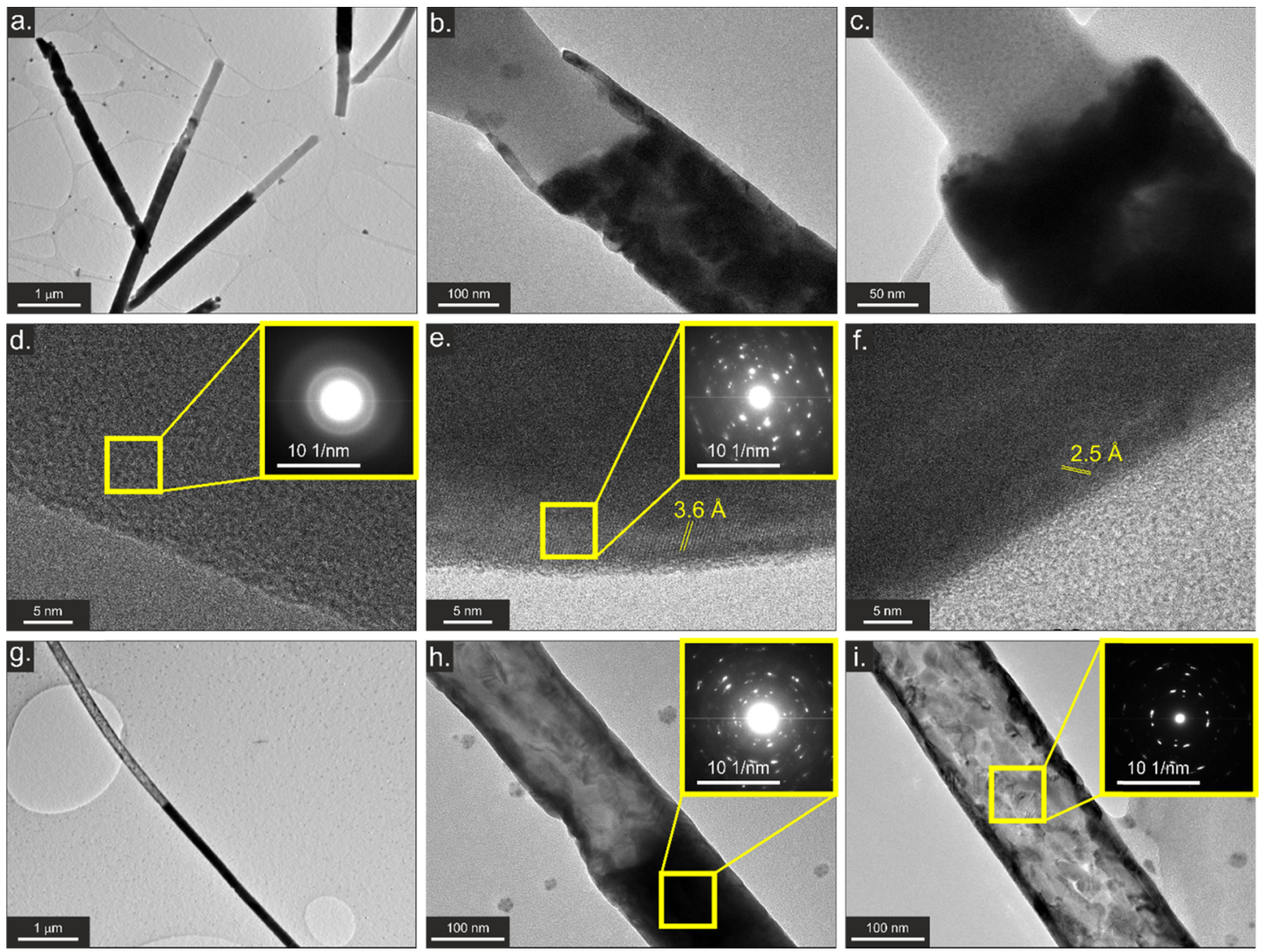

Figure 5. $(a-c, g-i)$ TEM images, $(d-f)$ high-resolution TEM (HR-TEM) images, and (insets in $d, e, h, i)$ diffraction patterns of $\mathrm{Cu}_{3}(\mathrm{BTC})_{2}$ nanowires with diameters of $(\mathrm{a}-\mathrm{f}) 210 \mathrm{~nm}$ and $(\mathrm{g}-\mathrm{i}) 130 \mathrm{~nm}$, which were both oxidized for $90 \mathrm{~min}$. The HR-TEM image in (d) was taken in the light-gray area of the nanowire shown in (b) and shows an amorphous structure as confirmed by its diffraction pattern (the inset in d). The HRTEM images in (e) and (f) were taken in the dark-gray area of the nanowire shown in (b) and show a crystalline structure as confirmed by the diffraction pattern shown as an inset in (e). The diffraction pattern in the inset in (h) was taken in the dark area of the nanowire shown in (h), whereas the diffraction pattern in the inset in (i) was taken in the lighter area.

conversion is in agreement with previous reports. In particular, Schäfer et al. ${ }^{44}$ showed that the availability of a native $\mathrm{Cu}_{2} \mathrm{O}$ layer and/or an oxidizing atmosphere is essential for the electrochemical conversion of $\mathrm{Cu}$ to $\mathrm{Cu}_{3}(\mathrm{BTC})_{2}$. These results therefore suggest that $\mathrm{Cu}_{2} \mathrm{O}$ is likely to be the intermediate of the conversion of $\mathrm{Cu}$ to $\mathrm{Cu}_{3}(\mathrm{BTC})_{2}$. Additional Fourier Transform Infrared (FT-IR) characterization on the HKUST-1 nanowires with a diameter of $260 \mathrm{~nm}$ can be found in Figure S6, in the Supporting Information. The FT-IR spectrum of the nanowires was compared with that of a bulk sample of the same MOF, and the peaks were assigned according to previous reports. $^{22,45}$

Thermogravimetric analysis/differential scanning calorimetry (TGA/DSC) curves of the $\mathrm{Cu}_{3}(\mathrm{BTC})_{2}$ nanowires with a diameter of $210 \mathrm{~nm}$ converted for $2 \mathrm{~h}$ and still embedded within the polycarbonate membrane are reported in Figure $3 \mathrm{~b}$. The TGA/DSC curves of the same sample after dissolution of the polycarbonate membrane can be found in Figure S7a. The main difference between those measurements is the absence of the small DSC peak observed at approximately $145{ }^{\circ} \mathrm{C}$, which is due to the glass transition of the polycarbonate template, and the large weight loss between 345 and $481{ }^{\circ} \mathrm{C}$ (and the accompanying DSC peak observed at $\sim 442{ }^{\circ} \mathrm{C}$ ), which is due to combustion of the polycarbonate template. The TGA/DSC measurement without the template (Figure $\mathrm{S} 7 \mathrm{a}$ ) reveals a small weight increase ( 1 wt \%) between 352 and $527^{\circ} \mathrm{C}$, which we interpret as the oxidation of unconverted $\mathrm{Cu}$, which is in accordance with the presented XRD patterns (Figures S3 and S5). These curves are compared with the TGA/DSC curves of a bulk sample of the same MOF and of an empty polycarbonate membrane without nanowires, as shown in Figure S7b,c, respectively (Supporting Information). The first exothermic DSC peak, centered at $329{ }^{\circ} \mathrm{C}$ (red arrow), is assigned to the decomposition of the $\mathrm{Cu}_{3}(\mathrm{BTC})_{2}$ nanowires, whereas two exothermic peaks centered at 441 and $523{ }^{\circ} \mathrm{C}$ are due to the decomposition of the polycarbonate membrane.

After XRD analysis, the polymer templates were dissolved in dichloromethane, and the $\mathrm{Cu}_{3}(\mathrm{BTC})_{2}$ nanowires that remained on the $\mathrm{Au}$ back electrode were investigated by scanning electron microscopy (SEM). Figure 4 shows the SEM images of the formed $\mathrm{Cu}_{3}(\mathrm{BTC})_{2} \mathrm{MOF}$ nanowires with different diameters. All nanowires exhibit a smooth surface as they adopted the shape and diameter of the hosting template channels. $^{46}$

Figure $5 \mathrm{a}-\mathrm{c}$ displays the transmission electron microscopy (TEM) images of $\mathrm{Cu}_{3}(\mathrm{BTC})_{2}$ nanowires with a diameter of $210 \mathrm{~nm}$ oxidized for $90 \mathrm{~min}$, which we assigned to complete MOF conversion according to the chronoamperograms presented in Figure S8. These TEM images visualize two different segments along the nanowires: a closer look into these segments shows that the lighter segment is amorphous (Figure $5 \mathrm{~d}$ ) and that the darker segment is crystalline with measured lattice fringe spacings of 3.6 or $2.5 \AA$ (Figure $5 e-f$ ). The lattice fringe spacing of $2.5 \AA$ can be associated either with 


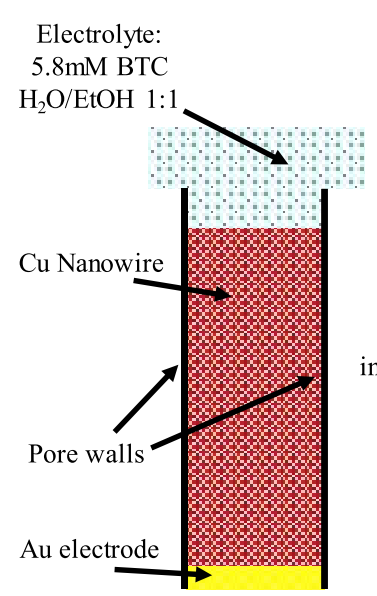

(a)

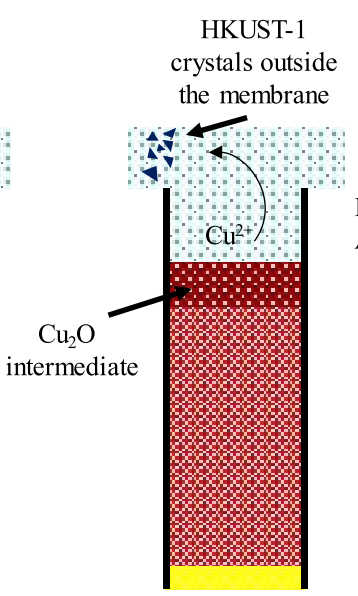

(b)

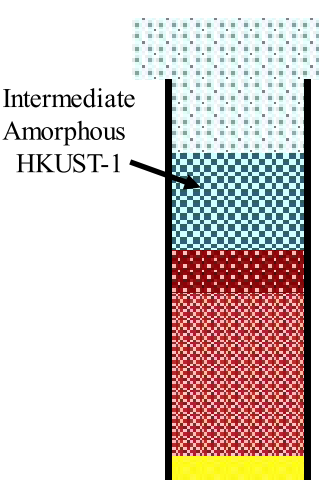

(c)

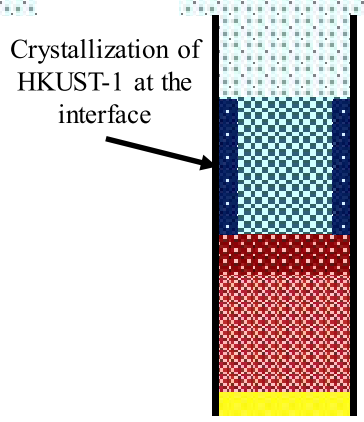

(d)

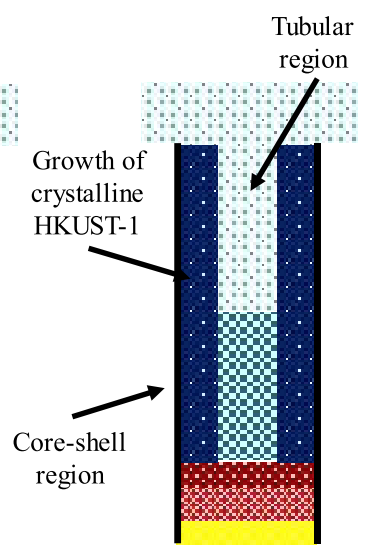

(e)

Figure 6. Schematic representation of a hypothetic mechanism of the electrochemical conversion of $\mathrm{Cu}$ nanowires into core-shell $\mathrm{Cu} \mathrm{u}_{3}(\mathrm{BTC})_{2}$ nanowires and nanotubes. (a) Template pore filled with a $\mathrm{Cu}$ nanowire; (b) first seconds of the electrochemical oxidation with the formation of $\mathrm{Cu}_{2} \mathrm{O}$ as an intermediate and diffusion of the excess of $\mathrm{Cu}^{2+}$ outside the pores; (c) formation of an amorphous phase of Cu $\mathrm{Cu}_{3}(\mathrm{BTC})_{2}$; (d) formation of crystalline $\mathrm{Cu}_{3}(\mathrm{BTC})_{2}$ at the interface with the pore wall; and (e) $\mathrm{Cu}_{3}(\mathrm{BTC})_{2}$ crystal growth with the formation of core-shell and tubular regions.

the (111) direction of $\mathrm{Cu}_{2} \mathrm{O}$, whose reflection was also shown by XRD (Figures $\mathrm{S} 3$ and $\mathrm{S} 5$ ), or to $\mathrm{Cu}_{3}(\mathrm{BTC}){ }_{2} \cdot{ }^{47}$ More convincingly, the lattice fringe spacing of $3.6 \AA$ cannot originate from $\mathrm{Cu}$ or any of its oxides $\left(\mathrm{CuO}, \mathrm{Cu}_{2} \mathrm{O}\right.$, or $\mathrm{Cu}_{4} \mathrm{O}_{3}$ ), whereas it was recorded as one of the many $d$-spacings available in $\mathrm{Cu}_{3}(\mathrm{BTC})_{2}{ }^{47}$ confirming the formation of crystalline $\mathrm{Cu}_{3}(\mathrm{BTC})_{2}$ MOF nanowires. We also observed that the crystalline MOF segment exhibits a diameter of $\sim 210$ $\mathrm{nm}$, which corresponds to the diameter of the template channels, whereas the diameter of the amorphous MOF segment is $\sim 160-190 \mathrm{~nm}$, thus smaller than that of the template channels (Figure 5a,c).

Figure $5 \mathrm{~g}-\mathrm{h}$ shows the connection between the two adjacent segments of a $\mathrm{Cu}_{3}(\mathrm{BTC})_{2}$ nanowire with a diameter of $130 \mathrm{~nm}$ oxidized for $90 \mathrm{~min}$; also in this case, a steady-state current was reached during MOF conversion. In this case, the diffraction pattern measured at the darker segment reveals a combination of crystalline and amorphous material (the inset in Figure 5h), whereas the diffraction pattern of the lighter segment, which in turn reveals a darker rim along the wire surface and a lighter core, exhibits only crystalline features (the inset in Figure 5i). Therefore, it seems that the darker segment represents a MOF wire where the amorphous part is surrounded by a layer of crystalline MOF, whereas the lighter segment could be a nanotube composed of crystalline MOF without an amorphous MOF core. Since also Figure 5b hints toward a core-shell structure with an amorphous core surrounded by a crystalline shell, this suggests that crystallization of the MOF nanowires might start from the interface between the MOF nanowire and the polymeric template.

Figure 6 shows a schematic representation of a hypothetic mechanism of the conversion of $\mathrm{Cu}$ nanowires into the observed core-shell HKUST-1 nanowires and nanotubes. A section of a $\mathrm{Cu}$ nanowire inside a template pore is represented in Figure 6a. During the conversion, $\mathrm{Cu}_{2} \mathrm{O}$ is formed as an intermediate, Figure $6 \mathrm{~b}$, which is in agreement with the XRD diffractograms in Figure S3 and previous studies found in the literature. ${ }^{44}$ It should also be highlighted that the conversion of $\mathrm{Cu}$ to $\mathrm{Cu}_{3}(\mathrm{BTC})_{2}$ determines a substantial volume expansion.
However, in our system, the crystallization is confined within the walls of the template's pores; therefore, the oxidation of the $\mathrm{Cu}$ wires generates an excess of $\mathrm{Cu}^{2+}$ ions. We imagine that these excess $\mathrm{Cu}^{2+}$ ions diffuse into the electrolyte outside the pores and react with the BTC away from the template; see Figure $6 \mathrm{~b}$. During the electrochemical oxidation, an amorphous phase of HKUST-1 is formed (Figure 6c), which then crystallizes at the interface of the pore walls (Figure 6d), forming a core-shell nanowire with a nanotube region upon further crystal growth, as shown in Figure 6e.

Further research will be needed to confirm this hypothesis. It must also be highlighted that it was not possible to determine the porosity of the obtained $\mathrm{Cu}_{3}(\mathrm{BTC})_{2}$ nanowires due to the very low sample throughput (less than $0.1 \mathrm{mg}$ per sample) of the presented synthetic procedure. Additionally, our attempt to perform elemental analysis of the synthesized nanowires proved unsuccessful, possibly due to the incomplete removal of the polycarbonate template (using additional plasma etching would have damaged the MOF nanostructures) and to the presence of the Au supporting layer.

Furthermore, it can be observed in Figure $5 b, c$ that the crystalline MOF phase did not develop completely homogeneous. To enhance the homogeneous formation of a crystalline MOF by templated electrodeposition as introduced here, the potential applied for the oxidation of the $\mathrm{Cu}$ nanowires and the electrolyte temperature should be optimized in further research so that the oxidation rate slows down, providing more time for the reaction between the as-formed $\mathrm{Cu}^{2+}$ ions and the $\mathrm{BTC}^{3-}$. Moreover, it is expected that a longer heat treatment of the MOF nanowires, either inside the electrolyte used for the conversion reaction or in a drying oven, could enhance the crystallization of the amorphous core of the $\mathrm{Cu}_{3}(\mathrm{BTC})_{2}$ nanowires, whose presence was assessed by TEM characterization, and which is also in agreement with a previous report. $^{43}$ Furthermore, it should be mentioned that the difference of $\sim 30 \mu \mathrm{A}$ between the steady-state currents as observed in the chronoamperograms of the conversion reaction with $\mathrm{Cu}$ nanowires (Figure 2) and the empty Aucoated templates (Figure S1) could be the result of a 

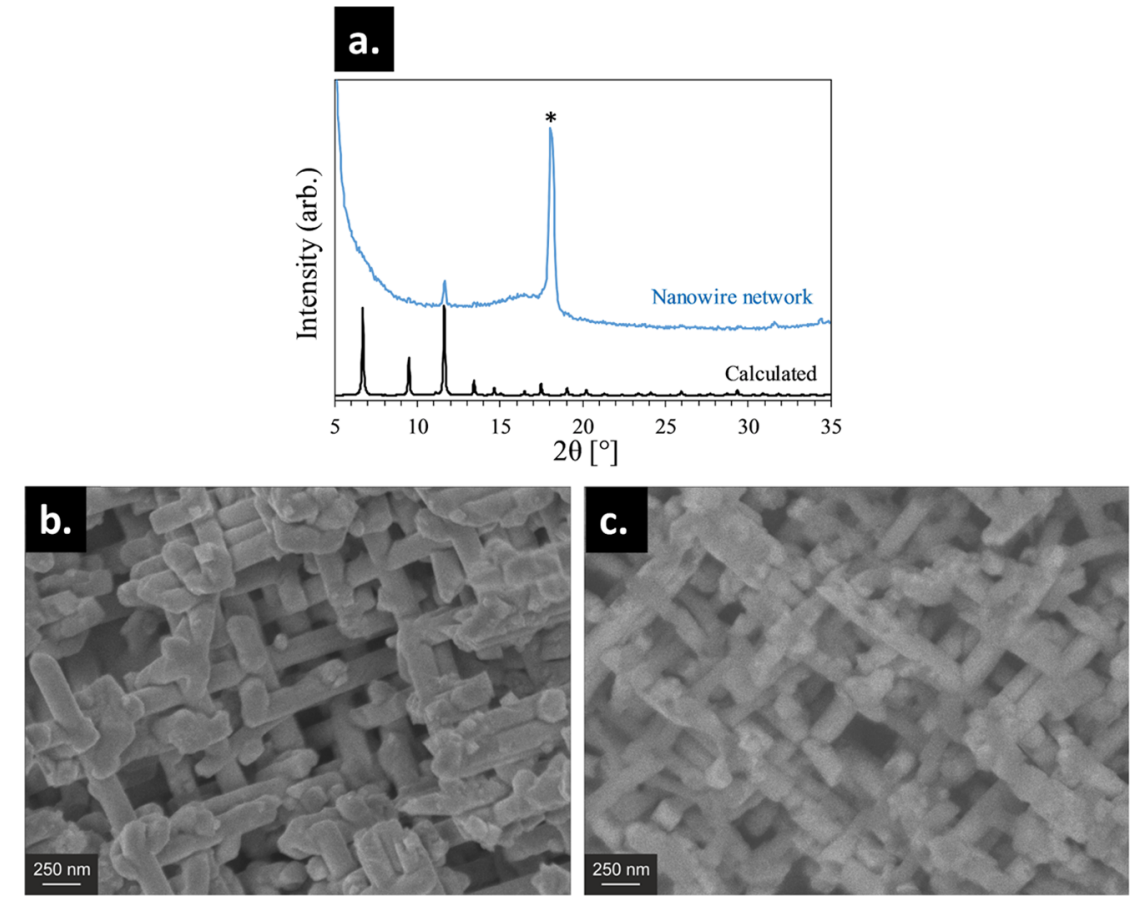

Figure 7. (a) XRD pattern of the $\mathrm{Cu}_{3}(\mathrm{BTC})_{2} \mathrm{MOF}$ nanowire network (blue curve) and the calculated XRD pattern for $\mathrm{Cu} u_{3}(\mathrm{BTC})_{2}{ }^{42}$ the reflection with an asterisk corresponds to the Teflon tape used to attach the sample on the XRD sample holder. (b) SEM images of a Cu nanowire network and (c) a $\mathrm{Cu}_{3}(\mathrm{BTC})_{2}$ nanowire network with a nanowire diameter of $170 \mathrm{~nm}$.
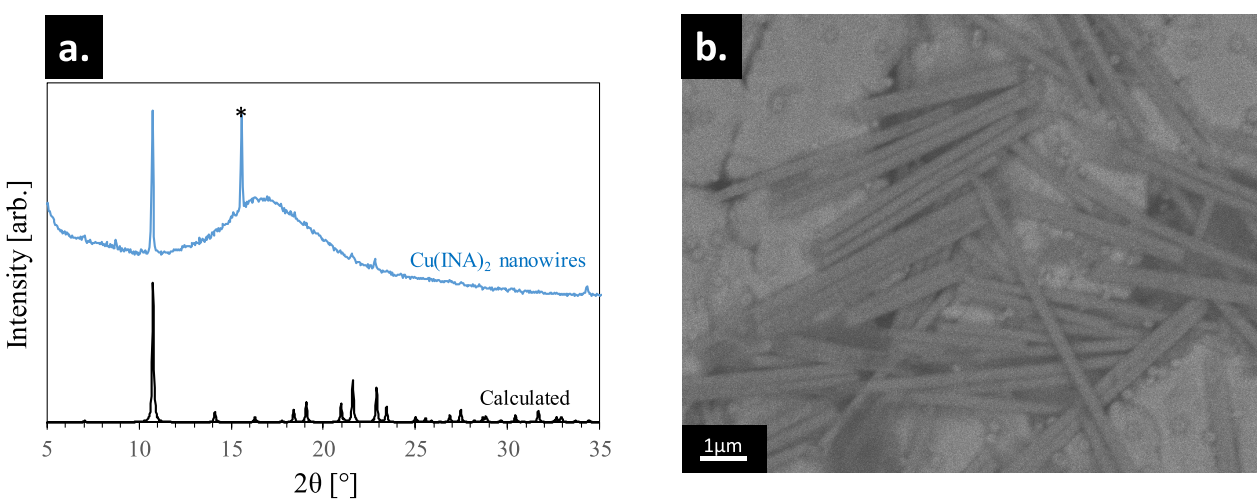

Figure 8. (a) $\mathrm{XRD}$ pattern of $\mathrm{Cu}(\mathrm{INA})_{2}$ nanowires with a diameter of $210 \mathrm{~nm}$ embedded in the polycarbonate template (blue curve) and the calculated XRD pattern for $\mathrm{Cu}$ (INA) 2 (black curve). ${ }^{41}$ The large amorphous halo ranging from $2 \theta=10$ to $25^{\circ}$ stems from the amorphous nature of the polycarbonate template, and the very intense reflection at $2 \theta \sim 15.9$, indicated with an asterisk, originates from an intermediate phase. ${ }^{41}$ (b) SEM image of $\mathrm{Cu}(\mathrm{INA})_{2}$ nanowires with a diameter of $\sim 260 \mathrm{~nm}$, after electrochemical conversion for $90 \mathrm{~min}$.

crystallization reaction that continues after the $\mathrm{Cu}$ nanowires were converted into (amorphous) MOF nanowires.

Three-Dimensionally Interconnected HKUST-1 Nanowire Networks. The application of MOF nanostructures in, e.g., gas sensors and photocatalysis, requires their assembly into three-dimensional macroscopic systems that can be implemented into devices. One way to integrate MOF nanowires into planar devices is to align them in between two electrodes by dielectrophoresis. ${ }^{48}$ On the other hand, three-dimensional assembly requires free-standing nanowires. In the case of the most common parallel nanowire arrays, the length of the wire is limited to an aspect ratio (length over diameter) of approximately 10. Above this, nanowires become fragile and break from the supporting electrode upon template removal. This limitation can be overcome using templates consisting of three-dimensionally interconnected nanochannels. ${ }^{35,36,49}$ This resulted in the synthesis of mechanically stable and three-dimensionally ordered MOF nanowire networks. These nanowire networks provide nanowires with high aspect ratio that are self-standing and do not break upon template removal. The XRD pattern in Figure $7 \mathrm{a}$ shows that the electrochemical conversion reaction took place inside these three-dimensionally interconnected nanochannel templates; the main reflection corresponding to the $\mathrm{Cu}_{3}(\mathrm{BTC})_{2}$ phase $(2 \theta=11.5)$ can be clearly identified, whereas the highest reflection (signed with an asterisk) corresponds to the Teflon tape used to attach the sample to the XRD sample holder (see Figure S9). Figure $7 \mathrm{~b}, \mathrm{c}$ shows the SEM images of a $\mathrm{Cu}$ nanowire network obtained by electrodeposition and a $\mathrm{Cu}_{3}$ (BTC) $)_{2}$ nanowire network formed by subsequent electrochemical oxidation inside the nanochannel template for $2 \mathrm{~h}$, respectively, after which the steady-state current was almost reached (Figure S10). 
$\mathrm{Cu}(\text { INA })_{2}$ Nanowires. The excellent versatility of the synthetic strategy developed here is demonstrated by fabricating a different type of technologically relevant MOF nanowires inside the same kind of templates: $\mathrm{Cu}(\mathrm{INA})_{2}$. $\mathrm{Cu}$ (INA $)_{2}$ is shown to be promising for the removal of hazardous materials from the environment by adsorption. ${ }^{41}$

Figure $8 \mathrm{a}$ shows the XRD pattern of the as-obtained $\mathrm{Cu}$ (INA) $)_{2}$ nanowires, still embedded in the porous polycarbonate membrane, together with the reference XRD pattern calculated from single-crystal XRD data published elsewhere. ${ }^{50}$ Due to the reduced amount of material and the presence of the polycarbonate membrane, not all of the reflections corresponding to the $\mathrm{Cu}(\mathrm{INA})_{2}$ crystalline phase can be found. However, the three most intense reflections (at $2 \theta \sim 10.7,21.6$, and 22.9) are present. A very intense reflection at $2 \theta \sim 15.9$, indicated with an asterisk, did not match with any of the reflections expected for $\mathrm{Cu}(\mathrm{INA})_{2}$. However, Tella et al. ${ }^{41}$ showed that this reflection originates from an intermediate phase during a solvent-free synthetic procedure to produce $\mathrm{Cu}(\mathrm{INA})_{2}$. Interestingly, during our electrochemical conversion, we see the formation of the same intermediate, despite the very different synthetic conditions. Moreover, we also noticed the presence of a reflection at $2 \theta=8.9^{\circ}$ with very low intensity, corresponding to an unidentified impurity, which is present in small amounts.

$\mathrm{Cu}$ and $\mathrm{Cu}_{2} \mathrm{O}$ reflections were also found for this sample (see Figure S11), originating from the incomplete conversion of $\mathrm{Cu}$ to $\mathrm{Cu}(\mathrm{INA})_{2}$ and $\mathrm{Cu}_{2} \mathrm{O}$ as an intermediate phase, respectively. Furthermore, it should be noted that the chronoamperograms measured during electrochemical conversion of the $\mathrm{Cu}$ nanowires into $\mathrm{Cu}(\mathrm{INA})_{2}$, Figure S12, looked similar to the ones shown in Figure 2 for $\mathrm{Cu}_{3}(\mathrm{BTC})_{2}$. These results therefore suggest that also in this case longer conversion times might be needed to achieve the complete conversion and crystallization of $\mathrm{Cu}$ nanowires into $\mathrm{Cu}(\mathrm{INA})_{2}$. Figure $8 \mathrm{~b}$ shows an SEM image of the $\mathrm{Cu}(\mathrm{INA})_{2}$ nanowires obtained after dissolving the polycarbonate membrane in dichloromethane. The nanowires show a diameter of $\sim 260$ $\mathrm{nm}$. With the preparation of Cu-MOFs with two different organic linkers, we demonstrate the versatility of the presented method for the formation of various MOF nanowires. $\mathrm{Cu}$ nanowires were used as the starting material for the synthesis of $\mathrm{Cu}-\mathrm{MOF}$ nanowires via electrochemical oxidation. $\mathrm{Cu}_{2} \mathrm{O}$ nanowires can also be used in the same oxidation reaction to form an MOF since $\mathrm{Cu}^{+}$ions can be electrochemically oxidized to $\mathrm{Cu}^{2+}$, which then reacts with the organic linker. By applying this principle of electrochemical conversion to other metal or metal oxide nanowires (e.g., $\mathrm{Cu}_{2} \mathrm{O}, \mathrm{Zn}$, or $\mathrm{Al}$ ), an avenue for the design of many more MOF nanowires is opened. ${ }^{24,51}$ By varying the morphology of the initial structures, MOFs with various geometries can also be produced, such as MOF nanocones from $\mathrm{Cu}$ nanocones. ${ }^{52}$ Furthermore, segmented and/or core-shell MOF nanostructures can be potentially synthesized since the electrochemical conversion conditions can be fine-tuned in such a way that the nanostructures will only be partly converted into the respective MOFs.

\section{CONCLUSIONS}

In this work, we successfully synthesized $\mathrm{Cu}_{3}(\mathrm{BTC})_{2}$ and $\mathrm{Cu}(\mathrm{INA})_{2}$ nanowires via a two-step electrochemical process: (1) $\mathrm{Cu}$ nanowires were electrodeposited within etched iontrack templates, which were (2) sequentially converted to the respective MOFs via electrochemical oxidation in a solution containing the required organic linkers. We demonstrate excellent control over the size and chemical nature of the deposited MOF nanowires, as shown by depositing MOF nanowires with different diameters $(80,130,210$, and $260 \mathrm{~nm})$ and various organic linker molecules (BTC and INA), respectively. Furthermore, we showed that this method also allows the direct synthesis of three-dimensionally interconnected MOF nanowire networks, which can be further applied as, e.g., gas sensors or photoelectrodes.

\section{EXPERIMENTAL DETAILS}

All chemicals used were purchased from commercial sources and used without further purification. Sodium hydroxide $(\mathrm{NaOH}, \geq 99 \%)$, ethanol (EtOH, $\geq 99.8 \%$ p.a.), and dichloromethane $\left(\mathrm{CH}_{2} \mathrm{Cl}_{2}\right.$, $>99.5 \%)$ were purchased from Carl Roth; copper sulfate pentahydrate $\left(\mathrm{CuSO}_{4} \cdot 5 \mathrm{H}_{2} \mathrm{O}\right.$, p.a. quality), 1,3,5-benzenetricarboxylic acid (BTC, 95\%), isonicotinic acid (INA, 99\%), and tributylmethylammonium methyl sulfate (MTBS, $\geq 95 \%$ ) were purchased from Sigma-Aldrich; sulfuric acid $\left(\mathrm{H}_{2} \mathrm{SO}_{4}, 98 \%\right)$ was purchased from Merck; and a commercial gold plating solution (Gold bath $\mathrm{SF}$ ) was purchased from METAKEM. Milli-Q water with a resistivity of $18.2 \mathrm{M} \Omega \cdot \mathrm{cm}$ was used in all experiments.

The polymer templates were prepared by ion-track nanotechnology, for which polycarbonate foils (Makrofol N, Bayer AG) with a thickness of $30 \mu \mathrm{m}$ were irradiated with Au ions with a total energy of $\sim 2 \mathrm{GeV}$ and a fluence of $\sim 10^{8}$ ions $/ \mathrm{cm}^{2}$ at the UNILAC linear accelerator of the GSI Helmholtz Centre for Heavy Ion Research. After irradiation, the ion tracks were selectively dissolved and enlarged by etching in an aqueous solution of $6 \mathrm{M} \mathrm{NaOH}$ at $50{ }^{\circ} \mathrm{C}$. Etching times of $2.5,5,7.5$, and $10 \mathrm{~min}$ resulted in polycarbonate membranes with pore diameters of approximately 80,130,210, and $260 \mathrm{~nm}$, respectively. Foils irradiated under normal incidence with $\sim 10^{8}$ ions/ $\mathrm{cm}^{2}$ were used to fabricate templates with parallel-oriented nanochannels. Foils irradiated in four consecutive steps under an angle of $45^{\circ}$ with respect to the surface normal with a total fluence of $4 \times\left(5 \times 10^{8}\right)$ ions $/ \mathrm{cm}^{2}$ were etched to form interconnected nanochannel networks. ${ }^{36,49,53}$

After etching, one side of the polycarbonate membranes was coated with $\sim 125 \mathrm{~nm}$ of Au using an Edwards S150B sputter coater. Next, the mechanical stability of this $\mathrm{Au}$ layer was enhanced by electrodeposition of a thicker $\mathrm{Au}$ layer using a commercial gold plating solution (AuSF, METAKEM) at room temperature by applying a potential of $-0.7 \mathrm{~V}$ versus a $\mathrm{Au}$ counter electrode in a two-electrode setup for $2 \mathrm{~h}$.

In all cases, $\mathrm{Cu}$ nanowires were electrodeposited inside the polycarbonate membranes from an aqueous solution containing $1.0 \mathrm{M}$ $\mathrm{CuSO}_{4}$ and $0.2 \mathrm{M} \mathrm{H}_{2} \mathrm{SO}_{4}$ at $60{ }^{\circ} \mathrm{C}$ by applying a potential of $-0.1 \mathrm{~V}$ in a two-electrode setup versus a $\mathrm{Cu}$ counter electrode for $8 \mathrm{~min}$. For this, the electrodeposition conditions were adapted from a previous report. $^{34}$ In the next step, $\mathrm{Cu}_{3}(\mathrm{BTC})_{2}$ was formed inside the nanochannels by electrochemical oxidation of the as-deposited $\mathrm{Cu}$ nanowires inside a $50 / 50 \mathrm{vol} \%$ ethanol/water solution containing 5.8 $\mathrm{mM} \mathrm{BTC}$ and $6.42 \mathrm{mM}$ MTBS at $55^{\circ} \mathrm{C}$ by applying $2.5 \mathrm{~V}$ versus a $\mathrm{Cu}$ counter electrode. For this, the conditions for electrochemical conversion were adapted from a previous study. ${ }^{54}$ During the oxidative dissolution of the $\mathrm{Cu}$ nanowires, the MOF is built up as soon as the as-formed $\mathrm{Cu}^{2+}$ ions bind to the $\mathrm{BTC}^{3-}$ ligands in the electrolyte solution.

For the deposition of $\mathrm{Cu}$ nanowire networks, surfactant (Dowfax $2 \mathrm{~A} 1,0.5 \mathrm{vol} \%$ ) was added to the $\mathrm{Cu}$ electrolyte to enhance the wetting capabilities of the electrolyte inside the template channels, ${ }^{53}$ and the $\mathrm{Cu}$ nanowire network was electrodeposited for $7 \mathrm{~min}$ using the same parameters as for the parallel $\mathrm{Cu}$ nanowires. Then, the $\mathrm{Cu}$ nanowire networks were converted to MOF nanowire networks in the same way as for the case of parallel MOF nanowires.

For the formation of $\mathrm{Cu}(\mathrm{INA})_{2}$ nanowires inside the template channels, the same conditions were used as for the $\mathrm{Cu}_{3}(\mathrm{BTC})_{2}$ nanowires, replacing BTC in the electrolyte by INA. 
X-ray diffraction (XRD) measurements of the nanostructures embedded in the polymer membrane were performed using a Bruker D2 powder diffractometer (equipped with a $\mathrm{Cu} \mathrm{K} \alpha$ source). TGA/ DSC measurements were done with a Netzsch (TGA) STA 449 C Jupiter with an integrated calorimeter (DSC). The measurements were performed in air with a gas flow of $500 \mathrm{~mL} / \mathrm{min}$ and a temperature range up to $800{ }^{\circ} \mathrm{C}$ with a heating rate of $10{ }^{\circ} \mathrm{C} / \mathrm{min}$. After releasing the nanowires from the template by dissolving the $\mathrm{PC}$ membrane in dichloromethane $\left(\mathrm{CH}_{2} \mathrm{Cl}_{2}\right)$, the nanowires were visualized using a JEOL JSM-7401F scanning electron microscope (SEM). For transmission electron microscopy (TEM), the MOF nanowires were transferred to a carbon-coated Au TEM grid by dropcasting a nanowire-containing $\mathrm{CH}_{2} \mathrm{Cl}_{2}$ solution. TEM measurements were performed using a JEOL ARM200CF with image $\mathrm{C}_{\mathrm{s}}$ corrector at a voltage of $80 \mathrm{kV}$ and a temperature of $-175^{\circ} \mathrm{C}$ to avoid degradation of the MOF, following the method from Wiktor et al. ${ }^{55}$ The IR measurements were done with a Bruker Tensor 27 FT-IRspectrometer with a diamond-ATR unit.

\section{ASSOCIATED CONTENT}

\section{S Supporting Information}

The Supporting Information is available free of charge on the ACS Publications website at DOI: 10.1021/acsami.9b04449.

Chronoamperograms measured in the absence of $\mathrm{Cu}$ nanowires; XRD patterns of the polycarbonate membrane and nanowires; and FT-IR spectra and TGA/DSC curves of nanowires (PDF)

\section{AUTHOR INFORMATION}

\section{Corresponding Authors}

*E-mail: m.e.toimilmolares@gsi.de. Tel: +49 (0)6159 711807 (M.E.T.-M.).

*E-mail: wouter.maijenburg@chemie.uni-halle.de. Tel: +49 (0)345 5528656 (A.W.M.).

ORCID

Francesco Caddeo: 0000-0002-2909-5379

A. Wouter Maijenburg: 0000-0002-2058-8345

\section{Author Contributions}

The manuscript was written through contributions of all authors.

\section{Notes}

The authors declare no competing financial interest.

\section{ACKNOWLEDGMENTS}

Financial support from the Alexander von Humboldt Foundation is gratefully acknowledged. Liana Movsesyan (GSI) and Christina Trautmann (GSI) are acknowledged for their useful discussions concerning the described research. Roberto Köferstein (MLU) is acknowledged for his help with the TGA/DSC measurements. M.E.T.-M. also thanks the DFG SPP-1613 for financial support. A.W.M. also thanks the BMBF (grant no. FKZ:03Z22HN11) for financial support. The preparation of the samples employed for this work is based on an UMAT irradiation experiment, which was performed at the beamline $\mathrm{X} 0$ at the GSI Helmholtzzentrum für Schwerionenforschung, Darmstadt (Germany) in the frame of FAIR-Phase 0.

\section{REFERENCES}

(1) Li, H.; Eddaoudi, M.; O’Keeffe, M.; Yaghi, O. M. Design and Synthesis of an Exceptionally Stable and Highly Porous MetalOrganic Framework. Nature 1999, 402, 276-279.
(2) Eddaoudi, M.; Kim, J.; Rosi, N.; Vodak, D.; Wachter, J.; O'keeffe, M.; Yaghi, O. M. Systematic Design of Pore Size and Functionality in Isoreticular MOFs and their Application in Methane Storage. Science 2002, 295, 469-472.

(3) Yuan, S.; Qin, J. S.; Li, J.; Huang, L.; Feng, L.; Fang, Y.; Lollar, C.; Pang, J.; Zhang, L.; Sun, D.; Alsalme, A.; Cagin, T.; Zhou, H. Retrosynthesis of Multi-component Metal-organic Frameworks. Nat. Commun. 2018, 9, No. 808.

(4) Rosi, N. L.; Eckert, J.; Eddaoudi, M.; Vodak, D. T.; Kim, J.; O'keeffe, M.; Yaghi, O. M. Hydrogen Storage in Microporous Metalorganic Frameworks. Science 2003, 300, 1127-1129.

(5) Chen, B.; Liang, C.; Yang, J.; Contreras, D. S.; Clancy, Y. L.; Lobkovsky, E. B.; Yaghi, O. M.; Dai, S. A Microporous MetalOrganic Framework for Gas-Chromatographic Separation of Alkanes. Angew. Chem., Int. Ed. 2006, 45, 1390-1393.

(6) Lu, G.; Hupp, J. T. Metal-organic Frameworks as Sensors: a ZIF-8 based Fabry- Pérot Device as a Selective Sensor for Chemical Vapors and Gases. J. Am. Chem. Soc. 2010, 132, 7832-7833.

(7) McKinlay, A. C.; Morris, R. E.; Horcajada, P.; Férey, G.; Gref, R.; Couvreur, P.; Serre, C. BioMOFs: Metal-organic Frameworks for Biological and Medical Applications. Angew. Chem., Int. Ed. 2010, 49, 6260-6266.

(8) Erickson, K. J.; Léonard, F.; Stavila, V.; Foster, M. E.; Spataru, C. D.; Jones, R. E.; Foley, B. M.; Hopkins, P. E.; Allendorf, M. D.; Talin, A. A. Thin Film Thermoelectric Metal-organic Framework with High Seebeck Coefficient and Low Thermal Conductivity. Adv. Mater. 2015, 27, 3453-3459.

(9) Nasalevich, M. A.; Van der Veen, M.; Kapteijn, F.; Gascon, J. Metal-organic Frameworks as Heterogeneous Photocatalysts: Advantages and Challenges. Cryst. Eng. Comm. 2014, 16, 4919-4926.

(10) Maina, J. W.; Schütz, J. A.; Grundy, L.; Des Ligneris, E.; Yi, Z.; Kong, L.; Pozo-Gonzalo, C.; Ionescu, M.; Dumée, L. F. Inorganic Nanoparticles/Metal Organic Framework Hybrid Membrane Reactors for Efficient Photocatalytic Conversion of $\mathrm{CO}_{2}$. ACS Appl. Mater. Interfaces 2017, 9, 35010-35017.

(11) Nguyen, T. N.; Kampouri, S.; Valizadeh, B.; Luo, W.; Ongari, D.; Planes, O. M.; Züttel, A.; Smit, B.; Stylianou, K. C. Photocatalytic Hydrogen Generation from a Visible-light Responsive Metal-organic Framework System: Stability versus Activity of Molybdenum Sulfide Co-catalysts. ACS Appl. Mater. Interfaces 2018, 10, 30035-30039.

(12) Fei, H.; Cohen, S. M. Metalation of a thiocatecholfunctionalized $\mathrm{Zr}$ (IV)-based Metal-Organic Framework for Selective C-H Functionalization. J. Am. Chem. Soc. 2015, 137, 2191-2194.

(13) Pullen, S.; Fei, H.; Orthaber, A.; Cohen, S. M.; Ott, S. Enhanced Photochemical Hydrogen Production by a Molecular Diiron Catalyst Incorporated into a Metal-organic Framework. J. Am. Chem. Soc. 2013, 135, 16997-17003.

(14) Flügel, E. A.; Ranft, A.; Haase, F.; Lotsch, B. V. Synthetic Routes Toward MOF Nanomorphologies. J. Mater. Chem. 2012, 22, 10119-10133.

(15) Bunzen, H.; Grzywa, M.; Hambach, M.; Spirkl, S.; Volkmer, D. From Micro to Nano: a Toolbox for Tuning Crystal Size and Morphology of Benzotriazolate-based Metal-organic Frameworks. Cryst. Growth Des. 2016, 16, 3190-3197.

(16) Seoane, B.; Zamaro, J. M.; Tellez, C.; Coronas, J. Sonocrystallization of Zeolitic Imidazolate Frameworks (ZIF-7, ZIF8, ZIF-11 and ZIF-20). CrystEngComm 2012, 14, 3103-3107.

(17) Morris, W.; Wang, S.; Cho, D.; Auyeung, E.; Li, P.; Farha, O. K.; Mirkin, C. A. Role of Modulators in Controlling the Colloidal Stability and Polydispersity of the UiO-66 Metal-Organic Framework. ACS Appl. Mater. Interfaces 2017, 9, 33413-33418.

(18) Zhao, Y.; Zhang, J.; Han, B.; Song, J.; Li, J.; Wang, Q. Metalorganic Framework Nanospheres with Well-ordered Mesopores Synthesized in an Ionic Liquid $/ \mathrm{CO}_{2} /$ surfactant system. Angew. Chem., Int. Ed. 2011, 50, 636-639.

(19) Faustini, M.; Kim, J.; Jeong, G. Y.; Kim, J. Y.; Moon, H. R.; Ahn, W. S.; Kim, D. P. Microfluidic Approach Toward Continuous and Ultrafast Synthesis of Metal-organic Framework Crystals and 
Hetero Structures in Confined Microdroplets. J. Am. Chem. Soc. 2013, $135,14619-14626$.

(20) Majewski, M. B.; Noh, H.; Islamoglu, T.; Farha, O. K. NanoMOFs: Little Crystallites for Substantial Applications. J. Mater. Chem. A 2018, 6, 7338-7350.

(21) Lan, X.; Huang, N.; Wang, J.; Wang, T. A General and Facile Strategy for Precisely Controlling the Crystal Size of Monodispersed Metal-organic Frameworks via Separating the Nucleation and Growth. Chem. Commun. 2018, 54, 584-587.

(22) Okada, K.; Ricco, R.; Tokudome, Y.; Styles, M. J.; Hill, A. J.; Takahashi, M.; Falcaro, P. Copper Conversion into $\mathrm{Cu}(\mathrm{OH})_{2}$ Nanotubes for Positioning $\mathrm{Cu}_{3}(\mathrm{BTC})_{2}$ MOF Crystals: Controlling the Growth on Flat Plates, 3d Architectures, and as Patterns. Adv. Funct. Mater. 2014, 24, 1969-1977.

(23) Al-Kutubi, H.; Gascon, J.; Sudhölter, E. J.; Rassaei, L. Electrosynthesis of Metal-organic Frameworks: Challenges and Opportunities. ChemElectroChem 2015, 2, 462-474.

(24) Martinez Joaristi, A.; Juan-Alcañiz, J.; Serra-Crespo, P.; Kapteijn, F.; Gascon, J. Electrochemical Synthesis of Some Archetypical $\mathrm{Zn}^{2+}, \mathrm{Cu}^{2+}$, and $\mathrm{Al}^{3+}$ Metal Organic Frameworks. Cryst. Growth Des. 2012, 12, 3489-3498.

(25) Ameloot, R.; Stappers, L.; Fransaer, J.; Alaerts, L.; Sels, B. F.; De Vos, D. E. Patterned Growth of Metal-organic Framework Coatings by Electrochemical Synthesis. Chem. Mater. 2009, 21, $2580-2582$.

(26) Van Assche, T. R.; Desmet, G.; Ameloot, R.; De Vos, D. E.; Terryn, H.; Denayer, J. F. Electrochemical Synthesis of thin HKUST1 Layers on Copper Mesh. Microporous Mesoporous Mater. 2012, 158, 209-213.

(27) Li, W. J.; Lü, J.; Gao, S. Y.; Li, Q. H.; Cao, R. Electrochemical Preparation of Metal-organic Framework Films for Fast Detection of Nitro Explosives. J. Mater. Chem. A 2014, 2, 19473-19478.

(28) Campagnol, N.; Van Assche, T.; Boudewijns, T.; Denayer, J.; Binnemans, K.; De Vos, D.; Fransaer, J. High Pressure, High Temperature Electrochemical Synthesis of Metal-organic Frameworks: Films of MIL-100 (Fe) and HKUST-1 in Different Morphologies. J. Mater. Chem. A 2013, 1, 5827-5830.

(29) Worrall, S. D.; Mann, H.; Rogers, A.; Bissett, M. A.; Attfield, M. P.; Dryfe, R. A. Electrochemical Deposition of Zeolitic Imidazolate Framework Electrode Coatings for Supercapacitor Electrodes. Electrochim. Acta 2016, 197, 228-240.

(30) Stassen, I.; Styles, M.; Van Assche, T.; Campagnol, N.; Fransaer, J.; Denayer, J.; Tan, J.-C.; Falcaro, P.; De Vos, D.; Ameloot, R. Electrochemical Film Deposition of the Zirconium Metal-organic Framework UiO-66 and Application in a Miniaturized Sorbent Trap. Chem. Mater. 2015, 27, 1801-1807.

(31) Li, W. J.; Tu, M.; Cao, R.; Fischer, R. A. Metal-organic Framework Thin Films: Electrochemical Fabrication Techniques and Corresponding Applications \& Perspectives. J. Mater. Chem. A 2016, 4, 12356-12369.

(32) Li, M.; Dincă, M. On the Mechanism of MOF-5 Formation under Cathodic Bias. Chem. Mater. 2015, 27, 3203-3206.

(33) Ameloot, R.; Pandey, L.; Van der Auweraer, M.; Alaerts, L.; Sels, B. F.; De Vos, D. E. Patterned Film Growth of Metal-organic Frameworks Based on Galvanic Displacement. Chem. Commun. 2010, 46, 3735-3737.

(34) Toimil-Molares, M. E. Characterization and Properties of Micro-and Nanowires of Controlled Size, Composition, and Geometry Fabricated by Electrodeposition and Ion-track Technology. Beilstein J. Nanotechnol. 2012, 3, 860.

(35) Movsesyan, L.; Maijenburg, A.; Goethals, N.; Sigle, W.; Spende, A.; Yang, F.; Kaiser, B.; Jaegermann, W.; Park, S-Y.; Mul, G.; Trautmann, C.; Toimil-Molares, M. E. ZnO Nanowire Networks as Photoanode Model Systems for Photoelectrochemical Applications. Nanomaterials 2018, 8, 693.

(36) Movsesyan, L.; Schubert, I.; Yeranyan, L.; Trautmann, C.; Toimil-Molares, M. E. Influence of Electrodeposition Parameters on the Structure and mMorphology of $\mathrm{ZnO}$ Nanowire Arrays and
Networks Synthesized in Etched ion-track Membranes. Semicond. Sci. Technol. 2015, 31, No. 014006.

(37) Penner, R. M.; Martin, C. R. Preparation and Electrochemical Characterization of Ultramicroelectrode Ensembles. Anal. Chem. 1987, 59, 2625-2630.

(38) Toimil-Molares, M. T.; Buschmann, V.; Dobrev, D.; Neumann, R.; Scholz, R.; Schuchert, I. U.; Vetter, J. Single-crystalline Copper Nanowires Produced by Electrochemical Deposition in Polymeric Ion Track Membranes. Adv. Mater. 2001, 13, 62-65.

(39) Arbulu, R. C.; Jiang, Y. B.; Peterson, E. J.; Qin, Y. MetalOrganic Framework (MOF) Nanorods, Nanotubes, and Nanowires. Angew. Chem., Int. Ed. 2018, 57, 5813-5817.

(40) Chui, S. S. Y.; Lo, S. M. F.; Charmant, J. P.; Orpen, A. G.; Williams, I. D. A Chemically Functionalizable Nanoporous Material $\left[\mathrm{Cu}_{3}(\mathrm{TMA})_{2}\left(\mathrm{H}_{2} \mathrm{O}\right)_{3}\right]_{\mathrm{n}}$. Science 1999, 283, 1148-1150.

(41) Tella, A. C.; Owalude, S. O.; Ojekanmi, C. A.; Oluwafemi, O. S. Synthesis of Copper-Isonicotinate Metal-organic Frameworks Simply by Mixing Solid Reactants and Investigation of Their Adsorptive Properties for the Removal of the Fluorescein Dye. New J. Chem. 2014, 38, 4494-4500.

(42) Yakovenko, A. A.; Reibenspies, J. H.; Bhuvanesh, N.; Zhou, H. C. Generation and Applications of Structure Envelopes for Porous Metal-organic Frameworks. J. Appl. Crystallogr. 2013, 46, 346-53.

(43) Ye, J. Y.; Liu, C. J. $\mathrm{Cu}_{3}(\mathrm{BTC})_{2}$ : CO oxidation over MOF Based Catalysts. Chem. Commun. 2011, 47, 2167-2169.

(44) Schäfer, P.; van der Veen, M. A.; Domke, K. F. Unraveling a Two-step Oxidation Mechanism in Electrochemical Cu-MOF Synthesis. Chem. Commun. 2016, 52, 4722-4725.

(45) Rowsell, J. L.; Yaghi, O. M. Effects of Functionalization, Catenation, and Variation of the Metal Oxide and Organic Linking Units on The Low-Pressure Hydrogen Adsorption Properties of Metal- organic Frameworks. J. Am. Chem. Soc. 2006, 128, 13041315.

(46) Müller, S.; Schötz, C.; Picht, O.; Sigle, W.; Kopold, P.; Rauber, M.; Alber, I.; Neumann, R.; Toimil-Molares, M. E. Electrochemical Synthesis of $\mathrm{Bi}_{1-x} \mathrm{Sb}_{\mathrm{x}}$ Nanowires with Simultaneous Control on Size, Composition, and Surface Roughness. Cryst. Growth Des. 2012, 12, 615-621.

(47) Wong-Ng, W.; Kaduk, J. A.; Siderius, D. L.; Allen, A. L.; Espinal, L.; Boyerinas, B. M.; Levin, I.; Suchomel, M. R.; Ilavky, J.; Li, L.; Williamson, I.; Cockayne, E.; Wu, H. Reference Diffraction Patterns, Microstructure, and Pore-size Distribution for the Copper (II) benzene-1,3,5-tricarboxylate Metal Organic Framework (CuBTC) Compounds. Powder Diffr. 2015, 30, 2-13.

(48) Maijenburg, A. W.; Maas, M. G.; Rodijk, E. J. B.; Ahmed, W.; Kooij, E. S.; Carlen, E. T.; Blank, D. H. A.; ten Elshof, J. E. Dielectrophoretic Alignment of Metal and Metal Oxide Nanowires and Nanotubes: A Universal set of Parameters for Bridging Prepatterned Microelectrodes. J. Colloid Interface Sci. 2011, 355, 486-493.

(49) Rauber, M.; Alber, I.; Müller, S.; Neumann, R.; Picht, O.; Roth, C.; Schökel, A.; Toimil-Molares, M. E.; Ensinger, W. Highly-ordered Supportless Three-dimensional Nanowire Networks with Tunable Complexity and Interwire Connectivity for Device Integration. Nano Lett. 2011, 11, 2304-2310.

(50) Lu, J. Y.; Babb, A. M. An Extremely Stable Open-framework Metal-organic Polymer with Expandable Structure and Selective Adsorption Capability. Chem. Commun. 2002, 13, 1340-1341.

(51) Silva, C. G.; Corma, A.; García, H. Metal-organic Frameworks as Semiconductors. J. Mater. Chem. 2010, 20, 3141-3156.

(52) Serbun, P.; Jordan, F.; Navitski, A.; Müller, G.; Alber, I.; Toimil-Molares, M. E.; Trautmann, C. Copper Nanocones Grown in Polymer Ion-track Membranes as Field Emitters. Eur. Phys. J.: Appl. Phys. 2012, 58, No. 10402.

(53) Wagner, M. F.; Völklein, F.; Reith, H.; Trautmann, C.; ToimilMolares, M. E. Fabrication and Thermoelectrical Characterization of Three-dimensional Nanowire Networks. Phys. Status Solidi A 2016, $213,610-619$. 
(54) Van de Voorde, B.; Ameloot, R.; Stassen, I.; Everaert, M.; De Vos, D.; Tan, J. C. Mechanical Properties of Electrochemically Synthesised Metal-organic Framework Thin Films. J. Mater. Chem. C 2013, 1, 7716-7724.

(55) Wiktor, C.; Turner, S.; Zacher, D.; Fischer, R. A.; Van Tendeloo, G. Imaging of Intact MOF-5 Nanocrystals by Advanced TEM at Liquid Nitrogen Temperature. Microporous Mesoporous Mater. 2012, 162, 131-135. 